\title{
Effect of milk types on the attributes of a glutinous rice wine-fermented yogurt-like product
}

\author{
Shaoying Gong, ${ }^{1} \oplus$ Peng Fei, ${ }^{2} \odot$ Aslam Ali, ${ }^{3} \odot$ Xiaolin Cai, ${ }^{1} \odot$ Wei Xue, ${ }^{4}$ Wen Jiang, ${ }^{5}$ and Ling Guo ${ }^{1 *} \odot$ \\ ${ }^{1}$ Key Laboratory of Dairy Science, Ministry of Education, College of Food Science, Northeast Agricultural University, Harbin 150030, China \\ ${ }^{2}$ College of Food and Bioengineering, Henan University of Science and Technology, Luoyang, 471023, China \\ ${ }^{3}$ Department of Agro-Processing, Bangabandhu Sheikh Mujibur Rahman Agricultural University, Gazipur-1706, Bangladesh \\ ${ }^{4}$ Heilongjiang Metrology Institute of Measurement and Verification, No. 99, Situ Street, Xiangfang District, Harbin, Heilongjiang, China 150036 \\ ${ }^{5}$ National Agricultural Standardization Monitoring and Research Center (Heilongjiang), No. 1218, Chuangxin'er Road, Songbei District, Harbin, \\ Heilongjiang, China 150028
}

\begin{abstract}
This study was conducted to analyze the effect of milk types on the attributes of the glutinous rice winefermented yogurt-like product named Kouwan Lao (KWL). Four types of raw milks were used in this study, including high temperature, long time (HTLT: H milk), HTLT milk supplemented with $3 \%$ skim milk powder (S milk), pasteurized milk (P milk), and ultra-high temperature milk (U milk). Microbiological compositions of the fermented glutinous rice and KWL at different stages were analyzed using PCR-denaturing gradient gel electrophoresis and gene sequencing based on $16 \mathrm{~S}$ rRNA and $26 \mathrm{~S}$ rRNA. The physicochemical properties of KWL samples were determined, and textural properties of those were analyzed using a texture analyzer (Jiawei Innovation and Technology Co. Ltd., Zhejiang Province, China). The microstructure of KWL samples was observed using scanning electron microscopy. The results showed that the milk types had significant influences on the bacterial composition of KWL. In the curdling process, the predominant bacteria of $\mathrm{H}$, $\mathrm{S}, \mathrm{P}$, and U KWL samples were Lactobacillus brevis, Janthinobacterium sp., Lactobacillus casei, and Streptococcus agalactiae, respectively. In the ripening process, the main strains in H KWL were Enterococcus faecium and Pediococcus pentosaceus. Lactobacillus casei and Lactobacillus paracasei were the dominant bacteria of U KWL. Lactobacillus casei was the main strain of $\mathrm{P}$ KWL, and no bacteria were detected in S KWL. Saccharomyces cerevisiae was the dominant fungus of KWL, and no significant effect of milk types on fungal
\end{abstract}

Received June 11, 2019.

Accepted September 17, 2019.

*Corresponding author: guoling@neau.edu.cn composition of KWL was found. The results of physicochemical properties showed that significant differences in protein contents were found in the KWL samples, and P KWL had the highest protein content. The fat content of U KWL was significantly higher than that of samples from the other 3 groups. The U KWL and P KWL showed lower moisture than that of the other 2 KWL samples. In addition, no significant difference in $\mathrm{pH}$ value was found in all samples. The results of texture analysis and microstructure showed that compared with other 3 types of KWL samples, the related mass parameters of U KWL were more advantageous and improved significantly with the increase of the heat treatment temperature of raw milk and the addition of skim milk powder. Our findings revealed the effects of milk types on microbial composition, physicochemical properties, textural properties, and microstructure of KWL, and provided a basic theory for the optimization and industrial production of KWL.

Key words: Kouwan Lao, milk type, bacterial and fungal diversity, texture property

\section{INTRODUCTION}

Yogurt and yogurt-like products are often consumed as healthy foods, and are a growing market in the dairy industry through the world (Matumoto-Pintro et al., 2011). To increase consumer interest in the health benefits of yogurt, a variety of food combinations have been used in production of yogurt and yogurt-like products, such as honey (Sert et al., 2017), grape seed oil (Mercan et al., 2018), and pineapple peel powder (Sah et al., 2016). In addition, some studies have also revealed the effect of additives on the fermentation performance of yogurt, including pine cone and sea buckthorn berries (Mercan and Akin, 2016; Terpou et al., 2019). The above background indicates that the development of yogurt and yogurt products is highly valued and has great potential. 
In China, the glutinous rice wine-fermented were used as a starter to produce a popular traditional yogurtlike product, called as Kouwan Lao (KWL). Kouwan Lao consists of soft curd appearance and a sweet-set gel induced from cow milk, which coagulated with the glutinous rice wine-fermented. It is a low-acid or nonsour-tasting yogurt-like product with slightly alcoholic flavor (Onyeneho et al., 1987). However, so far, little in-depth research has been done on KWL production and microbial structure.

For hundreds of years in China, fermented glutinous rice has utilized the yeast-ball or fungus as the starter cultured on a starch-rich substrate in a solid-state fermentation process (Su et al., 2005; Wang et al., 2008). Some strains have been found in the glutinous wine-fermented and their metabolites contained various amylolytic and proteolytic enzymes to exhibit notable milk-clotting ability and contributed to the texture of ultimate KWL (Ercolini et al., 2004; Lv et al., 2012). In addition, heat treatment and increasing TS in the raw milk could affect the development of the microbial community, the activity of milk rennet, and the texture of dairy products (Muyzer et al., 1993; Sert et al., 2017). Therefore, it is very meaningful to increase the understanding about the effect of milk types on microbiology composition of KWL for its mature large-scale industrial production.

Several rapid and reliable methods have been applied to identify strains that cannot be cultured using traditional methods; among these methods, the PCR-denaturing gradient gel electrophoresis (DGGE) technology was considered the most mature and commonly used, and has been widely used to reveal the microbial communities of dairy products (Flórez and Mayo, 2006). Using PCR-DGGE in combination with gene sequencing, the changes in diversity and microbial structure can be monitored in a timely manner at various stages of food products without isolation of strains (Grappin and Beuvier, 1997).

In this study, KWL was produced using different types of raw milk, including HTLT milk (H milk), HTLT milk with $3 \%$ skim milk power (S milk), pasteurized milk (P milk), and UHT milk (U milk). The PCR-DGGE in combination with gene sequencing was used to analyze the microbial communities of bacteria and fungi of KWL sample with different treatments during varying stages of fermentation. The effects of different milk types on properties such as chemical composition, textural properties, and microstructure of KWL were also assessed using the AOAC International method, texture analysis, and scanning electron microscopy, respectively.

\section{MATERIALS AND METHODS}

\section{Glutinous Rice Fermentation}

Rice wine was prepared as the exclusive starter of KWL according to the report of Onyeneho et al. (1987). Glutinous rice (Pan Fu Glutinous Rice, Liaoning Province, China) was washed and soaked in distilled water (rice:water $=1: 2$ by volume) for $60 \mathrm{~min}$ at room temperature $\left(22 \pm 2^{\circ} \mathrm{C}\right)$. The rice with soaking water were cooked for $20 \mathrm{~min}$ followed by cooling to $35^{\circ} \mathrm{C}$. The starter (Angel Yeast Co. Ltd., Hubei Province, China) was added into the cooled rice, then fermented in a closed environment at $30^{\circ} \mathrm{C}$ for $3 \mathrm{~d}$. The fermenting material was stirred up every day to wet all of the grain particles uniformly. After $3 \mathrm{~d}$ of fermentation, the fermented product was diluted with distilled water and re-incubated for additional $3 \mathrm{~d}$ followed by a filter to get the clear glutinous rice wine then and stored at $4^{\circ} \mathrm{C}$ for further study.

\section{Manufacturing of KWL}

Eight percent (wt/vol) of the glutinous rice wine and $8 \%$ (wt/vol) of sugar (bought from the local market) were individually added to different types of milk including $\mathrm{H}$ milk (raw milk was obtained from a local dairy farm and sterilized at $100^{\circ} \mathrm{C}$ for $15 \mathrm{~min}$ ), S milk (West Tang Biological Technology Co., Ltd., Shandong Province, China), P milk (Jiasheng Dairy Co., Ltd., Shandong Province, China), and U milk (Mengniu Dairy Co., Ltd., Inner Mongolia Autonomous Region, China). The mixed samples were fermented at $43^{\circ} \mathrm{C}$ until the curd was complete. Finished KWL samples were stored at $4^{\circ} \mathrm{C}$ and named as $\mathrm{H}$ KWL (made by HTLT milk), S KWL (made by HTLT milk supplemented with $3 \%$ skim milk powder), P KWL (made by pasteurized milk), and U KWL (made by UHT milk), respectively.

\section{PCR-DGGE Analysis}

The total DNA of KWL samples were extracted using the MiniBEST Universal Genomic DNA Extraction Kit (Ver 5.0, TaKaRa, Kusatsu, Japan). The primers sequences for V3-16S rRNA and D1-26S rRNA and PCR scheme were provided by previous reports (Muyzer et al., 1993; Cocolin et al., 2002). The DGGE analysis was performed on the Dcode System apparatus (Bio-Rad, Hercules, CA) following the method of Muyzer and Smalla (1998). Samples were applied to an $8 \%$ (wt/vol) polyacrylamide gel in $1 \times$ TAE buffer (40 mM Tris $\mathrm{HCl}, \mathrm{pH}$ 7.4, $20 \mathrm{~m} M$ sodium acetate, 1.0 
$\mathrm{m} M \mathrm{Na}_{2} \mathrm{EDTA}$ ) with a denaturing range of 35 to $60 \%$ for bacteria and 35 to $70 \%$ for fungi. Electrophoresis was performed at $20 \mathrm{~V}$ for $60 \mathrm{~min}$ and then at $130 \mathrm{~V}$ for $8 \mathrm{~h}$ at $60^{\circ} \mathrm{C}$ (Bio-Rad). The DNA bands were recovered and sequenced by the Beijing Genomics Institute (BGI, Beijing China). All sequences were identified in the GenBank database (http://www.ncbi.nlm.nih.gov/ BLAST/). Sequences with $97 \%$ of identity or higher were considered to represent the same species.

\section{Physicochemical Properties}

The chemical composition in terms of $\%$ moisture content (wt/wt), \% fat content (wt/wt), and \% protein content (wt/wt) of KWL samples made with different types of raw milk was analyzed based on the methods as stated by AOAC International (1997). The $\mathrm{pH}$ values of KWL samples were determined with the $\mathrm{pH}$ meter (model MP 220, Mettler Toledo, Barueri, SP, Brazil).

\section{Texture Profile}

The texture profile of KWL samples was performed according to previous study (Sandoval-Castilla et al., 2004) with some modifications. The texture indices of samples after standing for $30 \mathrm{~min}$ were measured using the texture analyzer (TA-XT plus texture analyzer, Jiawei Innovation and Technology Co., Ltd., Zhejiang Province, China). The texture analyzer was set at a pre-test speed of $2.0 \mathrm{~mm} / \mathrm{s}$, a measuring speed of 1.0 $\mathrm{mm} / \mathrm{s}$, a lateral velocity of $5.0 \mathrm{~mm} / \mathrm{s}$, a inductive force of $3.0 \mathrm{~N}$, and a compression distance of $10 \mathrm{~mm}$ using a probe of type $\mathrm{P} / 0.5$. The measuring times between intervals was set at $5.0 \mathrm{~s}$.

\section{Microstructure}

Scanning electron microscope observation was performed using the method reported by Sandoval-Castilla et al. (2004). The KWL samples were cut into $2 \times 2.5$ $\mathrm{mm}$ strips and fixed in $2.5 \%$ pentanediol followed by storage at $4^{\circ} \mathrm{C}$ for more than $90 \mathrm{~min}$. Samples after rinsing 3 times were dehydrated using $50 \%, 70 \%$, and $90 \%$ ethanol for $15 \mathrm{~min}$, respectively, and then dehydrated 3 times with 100\% ethanol for 15 min followed by rinsing with $100 \%$ butyl alcohol for $15 \mathrm{~min}$, and frozen at $-20^{\circ} \mathrm{C}$ for $30 \mathrm{~min}$. The samples were dried for $4 \mathrm{~h}$ followed by adhering to the sample stage of scanning electron microscopy. Over the scanning electron microscopy stage, a metal film with a thickness of 100 to $150 \AA$ was applied to the surfaces of samples by using an ion sputtering apparatus and the processed samples were prepared for inspection. The images were observed using the scanning electron microscope S3400N (Hitachi High-Tech Co. Ltd., Tokyo, Japan).

\section{Statistical Analysis}

For each treatment, data from independent replicate trials were obtained, and the means and the standard deviations were calculated. All data were analyzed using Duncan's multiple-range test (SPSS 17.0 software for windows, SPSS Inc., Chicago, IL). One-way ANOVA was used to assess the differences such as protein, fat, moisture contents, and $\mathrm{pH}$ values. Significant differences were accepted at $P<0.05$.

\section{RESULTS AND DISCUSSION}

\section{Effect of Milk Types on the Bacterial Community Structure in the KWL}

The DGGE analysis and gene sequencing were performed to reveal the effect of milk types on bacterial structure of KWL samples, as shown in Figure 1A and Table 1. The starters of the glutinous and glutinous rice wine were used as reference controls. The results showed significant differences in DGGE profiles of KWL prepared by different milk types, which suggested that the bacterial compositions of 4 groups KWL samples were different. Significant differences were also present in dominant strains of KWL samples. In detail, among the 4 types of raw milk, bacteria were detected only in $\mathrm{H}$ milk and identified as Streptococcus agalactiae, which indicated that in the KWL samples, the main bacteria come from glutinous rice wine. In the curdling process, the predominant bacteria of $\mathrm{H}, \mathrm{S}, \mathrm{P}$, and $\mathrm{U} \mathrm{KWL}$ samples were Lactobacillus brevis, Janthinobacterium sp., Lactobacillus casei, and Streptococcus agalactiae, respectively. In the ripening process, the main strains in H KWL were Enterococcus faecium and Pediococcus pentosaceus. Lactobacillus casei and Lactobacillus paracase $i$ were the dominant bacteria of U KWL. Lactobacillus casei still was the main strain of P KWL. In addition, no predominant bacteria were found in ripening of S KWL. These results indicated a significant effect of milk types on the bacterial composition of KWL during the curd and ripening process.

Analogously, $P$. pentosaceus in glutinous rice wine has been reported as the dominant bacteria in red yeast rice wine (Lv et al., 2012). In this study, S. agalactiae was found in the $\mathrm{H}$ milk and $\mathrm{U}$ KWL samples in the curd process, which was similar to the previous study of Liu et al. (2012), who detected S. agalactiae in the traditional fermented yak milk in Tibet. Lactobacillus 
Table 1. Identities of bands obtained from the bacterial community of Kouwan Lao (KWL) made by 4 types of milk

\begin{tabular}{|c|c|c|c|c|}
\hline Band no. ${ }^{1}$ & $\begin{array}{l}\text { Most similar sequence } \\
\text { relative (species) }\end{array}$ & $\begin{array}{l}\text { GenBank } \\
\text { accession no. }\end{array}$ & $\begin{array}{l}\text { Size } \\
\text { (bp) }\end{array}$ & $\begin{array}{c}\text { Identity } \\
(\%)\end{array}$ \\
\hline $11, \mathrm{H}-42$ & Pediococcus pentosaceus & JN851781.1 & 956 & 100 \\
\hline H-22 & Uncultured bacterium & EU647636.1 & 579 & 97 \\
\hline H-31 & Lactobacillus brevis & JN863608.1 & 949 & 99 \\
\hline H-41 & Enterococcus faecium & KY124655.1 & 1,442 & 99 \\
\hline S-51 & Uncultured bacterium & HE586845.1 & 560 & 99 \\
\hline $\mathrm{S}-54$ & Uncultured bacterium & JX543563.1 & 467 & 99 \\
\hline P-81, U-122 & Lactobacillus casei & KM921936.1 & 430 & 100 \\
\hline P-91 & L. casei & KM921935.1 & 430 & 100 \\
\hline U-121 & Lactobacillus paracasei & HQ697671.1 & 535 & 98 \\
\hline U-123 & L. casei & KM921936.1 & 430 & 98 \\
\hline
\end{tabular}

${ }_{1}^{1} 1$ = glutinous rice wine; H-22, H-23 = high temperature, long time (HTLT) milk; H-31 = curd of H KWL (KWL made by HTLT milk); H-41, $\mathrm{H}-42=$ ripened of $\mathrm{H}$ KWL; S-51 to S-54 = curd of S KWL (KWL made by HTLT milk with 3\% skim milk); P-81 = curd of P KWL (KWL made by pasteurized milk); P-91 = ripened of P KWL; U-112 = curd of U KWL (KWL made by UHT milk); U-121 to U-123 = ripened of U KWL.

genus was the predominant strains in the curding stage of $\mathrm{H}$ and $\mathrm{P}$ KWL, and also was detected in other traditional fermented dairy products, such as yogurt-like product with added grape seed oil, Koumiss fermented with mare's milk, and milk bread (Rahman et al., 2009; Mercan et al., 2018; Guo et al., 2019). Janthinobacterium sp. detected from the curd of S KWL usually exists in soil and the environments where there may be contact with starter and raw milk (Gong et al., 2017). Enterococcus faecalis, as nonstarter lactic acid bacteria, was the one of main strains in ripening of $\mathrm{H} \mathrm{KWL}$, and also was found in Turkish white cheese (Ispirli et al., 2016). Lactobacillus casei and L. paracasei detected from $\mathrm{P}$ and $\mathrm{U}$ KWL have been reported to occur in sheep yogurt (Haghshenas et al., 2015).

\section{Effect of Milk Types on the Fungal Community Structure in KWL}

As shown in Figure 1B, the diversity of fungi in KWL was lower, especially compared with that of bacteria. The gene sequencing results corresponding to the bands in the DGGE picture are given in Table 2. The results showed that the fungus was not detected in all raw milk samples, and the dominant fungi in glutinous rice wine consisted of Clavispora lusitaniae, Wickerhamomyces

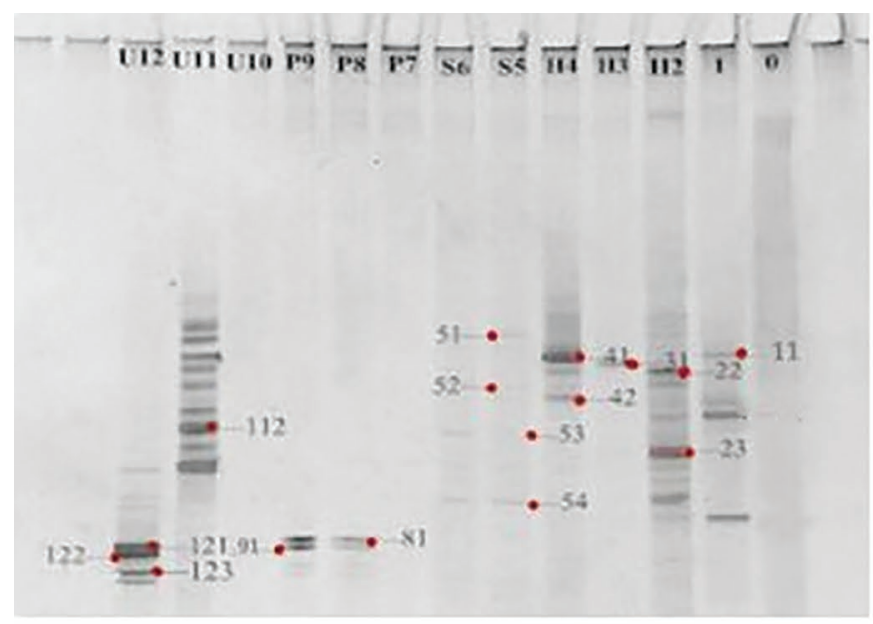

A

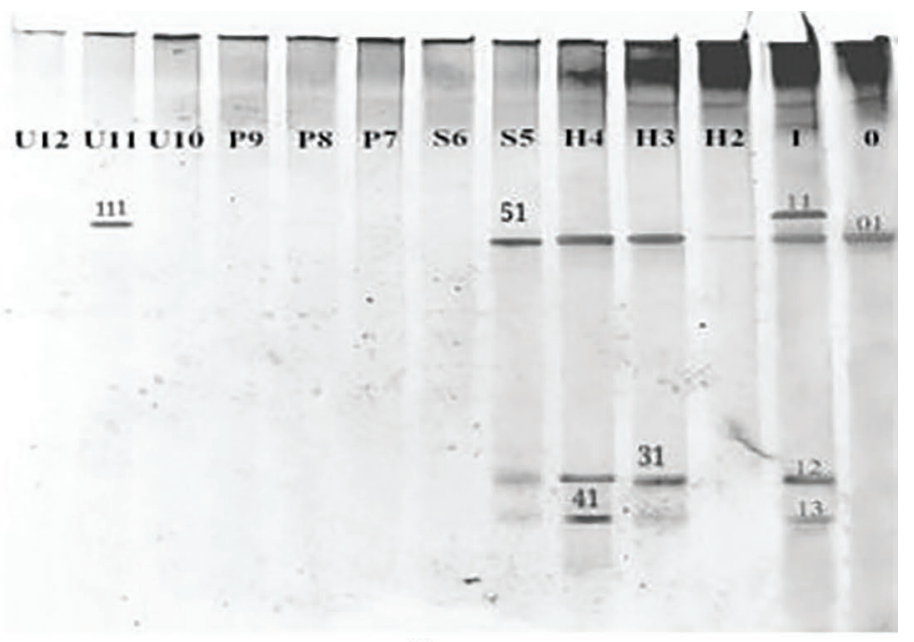

B

Figure 1. The denaturing gradient gel electrophoresis separation patterns of PCR amplified segments of the V3 region of bacterial $16 \mathrm{~S}$ rRNA gene (A) and fungal 26S rRNA gene (B) derived from Kouwan Lao (KWL) made from 4 types of milk. Lanes: $0=$ starters of the glutinous; 1 = glutinous rice wine; H2-H4, high temperature, long time (HTLT) milk = curd of H KWL (KWL made by HTLT milk), ripened of H KWL; S5-S6 = curd of S KWL (KWL made by HTLT milk with 3\% skim milk), ripened of S KWL; P7-P9 = pasteurized milk, curd of P KWL (KWL made by pasteurized milk), ripened P KWL; U10-U12, UHT milk, curd of U KWL (KWL made by UHT milk), ripened U KWL. Unnumbered bands were not identified. 
Table 2. Identities of bands obtained from the fungal community of Kouwan Lao (KWL) made by 4 types of milk

\begin{tabular}{|c|c|c|c|c|}
\hline Band no. ${ }^{1}$ & $\begin{array}{l}\text { Most similar sequence } \\
\text { relative (species) }\end{array}$ & $\begin{array}{l}\text { GenBank } \\
\text { accession no. }\end{array}$ & $\begin{array}{l}\text { Size } \\
\text { (bp) }\end{array}$ & $\begin{array}{l}\text { Identity } \\
(\%)\end{array}$ \\
\hline 01 & Rhizopus oryzae & KT160362.1 & 720 & 99 \\
\hline $31,41,51,111$ & Saccharomyces cerevisiae & EU441887.1 & 627 & 100 \\
\hline
\end{tabular}

${ }^{1} 01=$ starters of the glutinous; 11 to $13=$ glutinous rice wine; $31=$ the curd of H KWL [KWL made by high temperature, long time (HTLT) milk]; $41=$ ripened of $\mathrm{H}$ KWL; $51=$ curd of S KWL (KWL made by HTLT milk with $3 \%$ skim milk); $111=$ curd of U KWL (KWL made by UHT milk).

anomalous, and Rhizopus oryzae, which was similar to the study of Wang et al. (2008) and Thanh et al. (2016). Furthermore, Rhizopus oryzae as the main strain of glutinous rice wine also plays an important role in the fermentation of wine because it could secrete amylase (Wang et al., 2008; Lv et al., 2012). During the curdling process of KWL, Saccharomyces cerevisiae was present in $\mathrm{H}, \mathrm{S}$, and $\mathrm{U} \mathrm{KWL}$, whereas no fungus was detected in P KWL. In the ripening process, the fungus was detected only in $\mathrm{H} \mathrm{KWL}$, and identified as S. cerevisiae. Similarly, in previous studies, S. cerevisiae also was found in Japanese sake, Chinese rice wine, and Indonesian ragi (Wang et al., 2012; Li et al., 2014).

However, in general, milk types did not cause significant differences in fungal composition of KWL.

\section{Effect of Milk Types on the Physicochemical Properties of KWL}

The contents of protein, fat, moisture, and values of $\mathrm{pH}$ of $\mathrm{H}, \mathrm{S}, \mathrm{P}$, and $\mathrm{U}$ KWL samples were measured and shown in Table 3. Significant differences $(P<0.05)$ in protein contents have been found in the KWL samples made by 4 types of milk, among them, P KWL had the highest protein content, whereas the protein content of $\mathrm{H}$ KWL was the lowest. The fat content of U KWL was significantly higher than that of other 3 group samples $(P<0.05)$. The $\mathrm{U}$ and $\mathrm{P}$ KWL showed lower moisture than that of other $2 \mathrm{KWL}$ samples $(P<0.05)$. In addition, the difference in $\mathrm{pH}$ values was not significant in all samples $(P>0.05)$.
The physicochemical properties of milk can be greatly affected by the thermal sterilization parameters of raw milk. Célia et al. (2017) reported that the highest protein content was found in yogurt produced by pasteurized milk compared with UHT and raw refrigerated milk, which is agreement with our study. Because skim milk powder was added to $\mathrm{S}$ milk, the protein content of the S KWL was higher than H KWL. The fat content in the dairy products is reported to be related to the lipolysis of fungi, especially Saccharomyces, which also was detected in the finished products of $\mathrm{H} \mathrm{KWL}$. Further, the difference of $\mathrm{pH}$ value was not significant in all samples, which was similar to a previous study (Célia et al., 2017).

\section{Effect of Milk Types on the Textural Properties of KWL}

As shown in Table 4, the effect of milk type on the textural properties of KWL was revealed. The results showed that U and P KWL samples had higher hardness, springiness, chewiness, and resilience than $\mathrm{H}$ and S KWL $(P<0.05)$, and the hardness of $\mathrm{U}$ KWL was highest in all KWL samples. These suggest that UHT milk is more advantageous in the quality control of the texture of KWL, the quality of texture increases with the increase of heat treatment temperature of raw milk. Previous studies have shown that heat treatment of raw milk, fat, and protein content could influence the textural properties of dairy products, especially hardness, gumminess, and springiness (Krasaekoopt et al., 2004;

Table 3. Chemical indexes of Kouwan Lao (KWL; mean $\pm \mathrm{SD} ; \mathrm{n}=3$ )

\begin{tabular}{lcccc}
\hline Type $^{1}$ & Protein $(\%)$ & Fat $(\%)$ & Moisture $(\%)$ & $\mathrm{pH}$ \\
\hline $\mathrm{H}$ & $3.28 \pm 0.09^{\mathrm{a}}$ & $3.35 \pm 0.14^{\mathrm{b}}$ & $84.22 \pm 0.12^{\mathrm{a}}$ & $6.23 \pm 0.21^{\mathrm{a}}$ \\
$\mathrm{S}$ & $3.64 \pm 0.10^{\mathrm{b}}$ & $3.31 \pm 0.02^{\mathrm{b}}$ & $83.19 \pm 0.17^{\mathrm{b}}$ & $6.30 \pm 0.08^{\mathrm{a}}$ \\
$\mathrm{P}$ & $4.72 \pm 0.16^{\mathrm{c}}$ & $3.54 \pm 0.24^{\mathrm{b}}$ & $79.99 \pm 0.07^{\mathrm{c}}$ & $6.09 \pm 0.13^{\mathrm{a}}$ \\
$\mathrm{U}$ & $4.45 \pm 0.12^{\mathrm{d}}$ & $3.98 \pm 0.04^{\mathrm{a}}$ & $80.22 \pm 0.20^{\mathrm{c}}$ & $6.13 \pm 0.13^{\mathrm{a}}$ \\
\hline
\end{tabular}

${ }^{\mathrm{a}-\mathrm{d}}$ Values with different superscripts within the same column differ significantly $(P<0.05)$.

${ }^{1} \mathrm{H}=$ KWL made by high temperature, long time (HTLT) milk; $\mathrm{S}=$ KWL made by HTLT milk with $3 \%$ skim milk powder; $\mathrm{P}=$ KWL made by pasteurized milk; $\mathrm{U}=$ KWL made by UHT milk. 
Table 4. Textural indexes of Kouwan Lao (KWL) made by different types of milk; mean \pm SD; $\mathrm{n}=3$

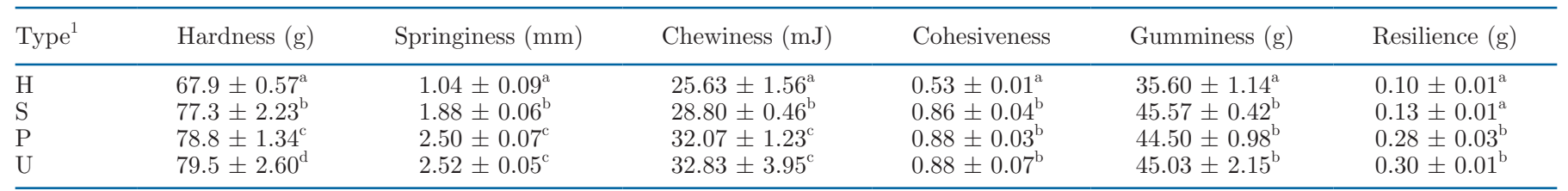

${ }^{\mathrm{a}-\mathrm{d}}$ Values with different superscripts within the same column differ significantly $(P<0.05)$.

${ }^{1} \mathrm{H}=$ KWL made by high temperature, long time (HTLT) milk; $\mathrm{S}=$ KWL made by HTLT milk with $3 \%$ skim milk powder; $\mathrm{P}=\mathrm{KWL}$ made by pasteurized milk; $\mathrm{U}=\mathrm{KWL}$ made by UHT milk.

Lee and Lucy, 2006; Akgun et al., 2016), and found that a more compact texture was easier to form in dairy products made by UHT milk, which was similar to our findings. In addition, in our study, compared with $\mathrm{H}$ KWL sample, the S KWL samples adding $3 \%$ of skim milk powder showed a significant advantage in the tex-

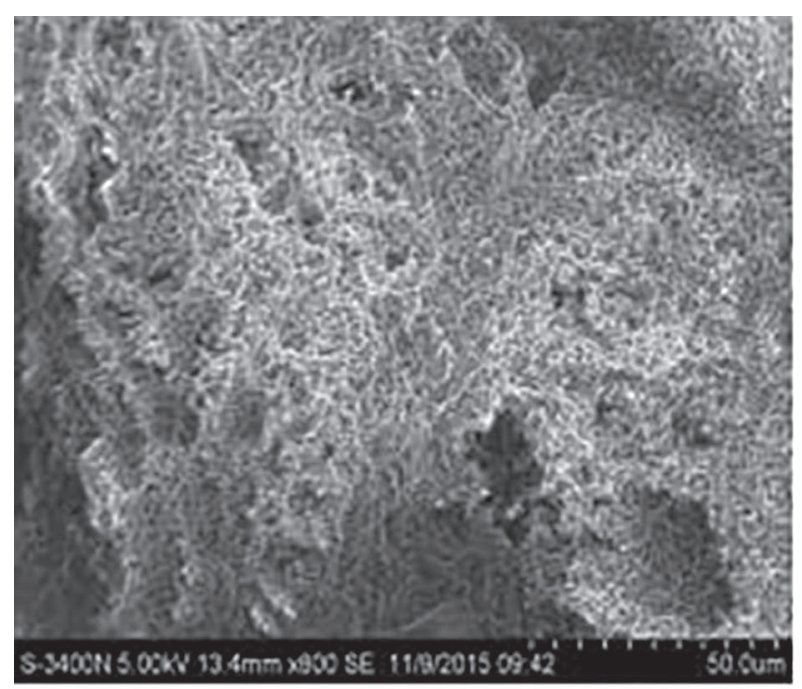

A

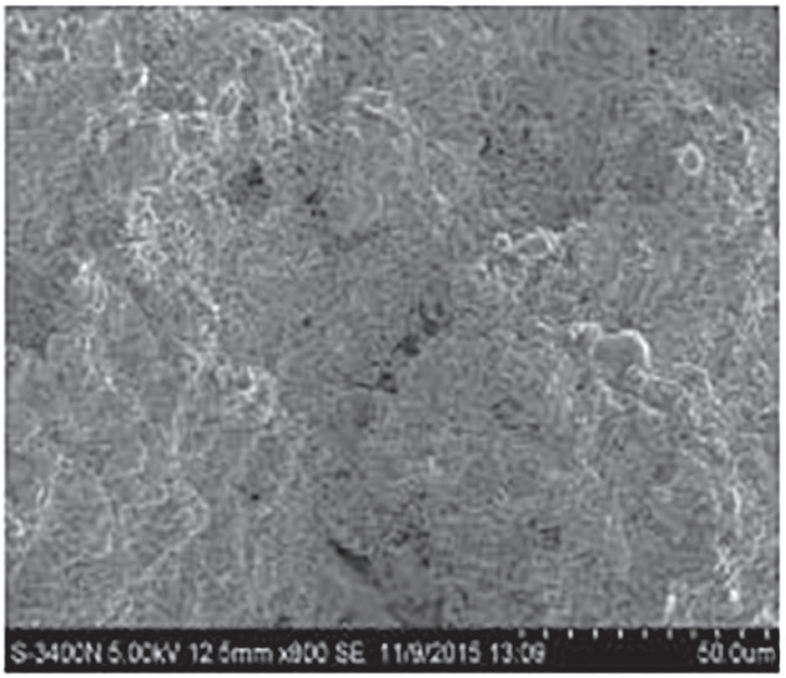

C

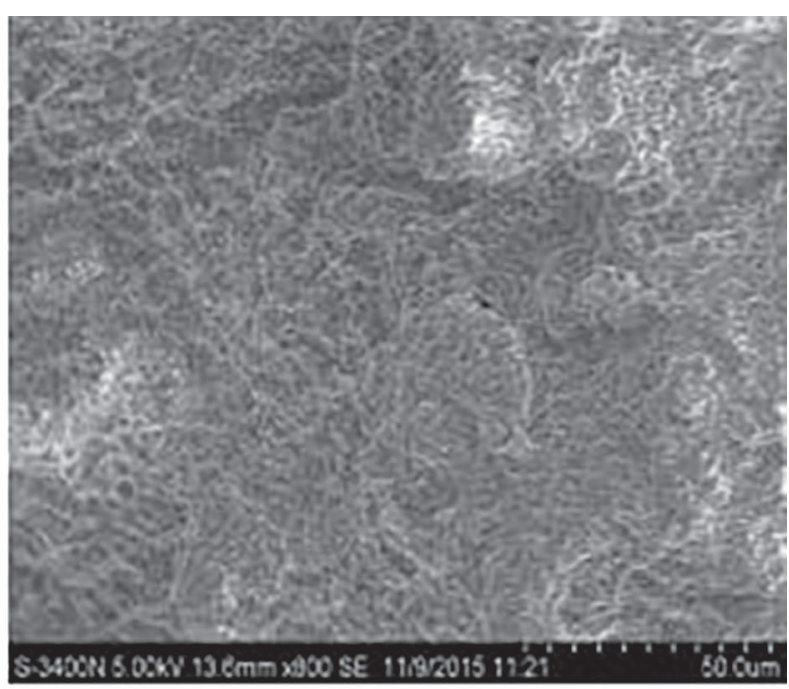

B

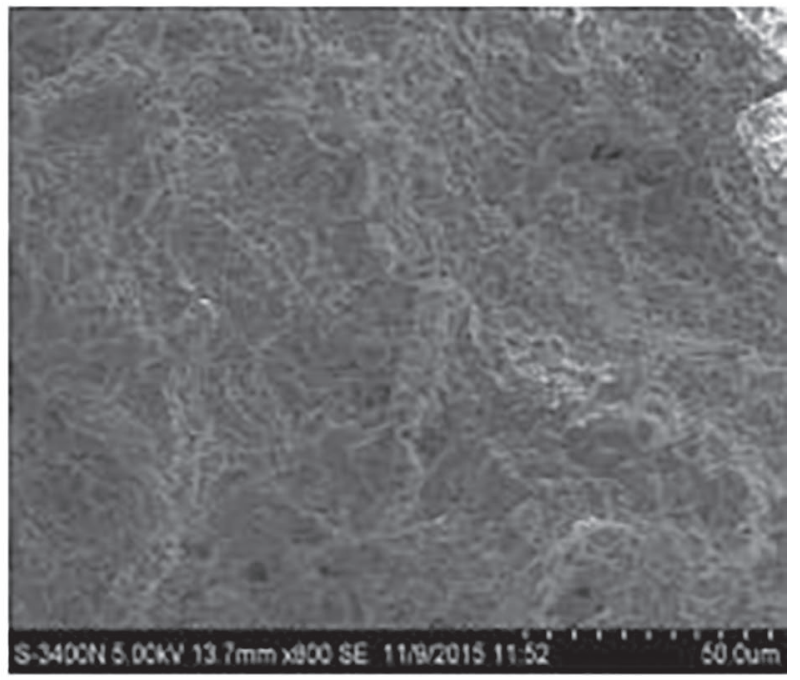

D

Figure 2. The microstructure of Kouwan Lao (KWL; A-D) made by 4 types of milk: (A) H KWL [KWL made by high temperature, long time (HTLT) milk]; (B) S KWL (KWL made by HTLT milk with $3 \%$ skim milk); (C) P KWL (KWL made by pasteurized milk); and (D) U KWL (KWL made by UHT milk). 
ture feature, which was consistent with previous studies (Sandoval-Castilla et al., 2004; Akgun et al., 2016).

\section{Effect of Milk Types on the Microstructure of KWL}

The scanning electron microscopy images indicated obvious differences in microstructure of KWL samples made from different types of milk (Figure 2). Among the $4 \mathrm{KWL}$ samples, the curd of the U KWL sample was the closest, smoothest, and most homogeneous; in contrast, curd quality of $\mathrm{H}$ KWL was the most overlooked, with large pores and rough on the curdling surface of samples. These may be because the higher preheat treatment temperature could accelerate the fusion of proteins, leading to more interconnected and dense gel networks (Lucey and Singh, 1999). In addition, compared with the H KWL sample, the microstructure of S KWL samples adding 3\% of skim milk powder was smooth and uniform, which was similar to the report of Park et al. (2007), who found the microstructure of goat milk yogurt with added bovine skim milk powder was smoother and more friable. Desai et al. (2013) indicated that the addition of skim milk powder could increase the graininess, viscosity, and cohesiveness, thereby improving the microstructure of the dairy products.

\section{CONCLUSIONS}

The data of this study indicated the effects of milk types on the attributes of KWL, including microbial composition, physicochemical properties, texture properties, and microstructure. Our findings showed that the milk types significantly affected the bacterial composition rather than the fungal structure in KWL. The chemical composition of the KWL product was also related to the types of raw milk, but the $\mathrm{pH}$ was not affected. With the increase of heat treatment temperature and the addition of skim milk powder, the texture and microstructure of KWL were closer, smoother, and more homogeneous. Therefore, in industrial production of KWL, it is suggested to shorten the curd time and improve product quality by using UHT milk with skim milk powder.

\section{ACKNOWLEDGMENTS}

The authors thank the anonymous reviewers and editors for their valuable advice. The authors thank Wenkui Guo for technical assistance and Xinhuai Zhao for writing assistance (Key Laboratory of Dairy Science, Ministry of Education, College of Food Science, Northeast Agricultural University, Harbin, China). The research was supported by Open Fund of the Key Laboratory of Dairy Science of the Ministry of Education at Northeast Agricultural University (2017KLDS06). We thank LetPub (www.letpub.com) for its linguistic assistance during the preparation of the manuscript. We certify that there is no conflict of interest with any financial organization regarding the material discussed in the manuscript.

\section{REFERENCES}

Akgun, A., F. Yazici, and H. A. Gulec. 2016. Effect of reduced fat content on the physicochemical and microbiological properties of buffalo milk yogurt. LWT Food Sci. Technol. 74:521-527.

AOAC International. 1997. Official Methods of Analysis. 16th ed. AOAC International, Gaithersburg, MD.

Célia, J. A., M. A. P. D. Silva, K. B. D. Oliveira, D. G. Souza, L. C. D. M. Silva, and E. S. Nicolau. 2017. Influence of heat treatment on physicochemical and rheological characteristics of natural yogurts. Semin. Cienc. Agrar. 38:2489-2504.

Cocolin, L., D. Aggio, M. Manzano, C. Cantoni, and G. Comi. 2002. An application of PCR-DGGE analysis to profile the yeast populations in raw milk. Int. Dairy J. 12:407-411.

Desai, N. T., L. Shepard, and M. A. Drake. 2013. Sensory properties and drivers of liking for Greek yogurts. J. Dairy Sci. 96:7454-7466.

Ercolini, D., G. Mauriello, G. Blaiotta, G. Moschetti, and S. Coppola. 2004. PCR-DGGE fingerprints of microbial succession during a manufacture of traditional water buffalo mozzarella cheese. J. Appl. Microbiol. 96:263-270.

Flórez, A. B., and B. Mayo. 2006. Microbial diversity and succession during the manufacture and ripening of traditional, Spanish, blue-veined Cabrales cheese, as determined by PCR-DGGE. Int. J. Food Microbiol. 110:165-171.

Gong, X., S. Skrivergaard, B. S. Korsgaard, L. Schreiber, L. P. G. Marshall, K. Finster, and A. Schramm. 2017. High quality draft genome sequence of Janthinobacterium psychrotolerans sp. nov., isolated from a frozen freshwater pond. Stand. Genomic Sci. 12:8.

Grappin, R., and E. Beuvier. 1997. Possible implications of milk pasteurization on the manufacture and sensory quality of ripened cheese: A review. Int. Dairy J. 7:6-7.

Guo, L., M. Ya, Y. Guo, W. Xu, C. Li, J. Sun, J. Zhu, and J. Qian. 2019. Study of bacterial and fungal community structures in traditional koumiss from Inner Mongolia. J. Dairy Sci. 102:1972-1984.

Haghshenas, B., Y. Nami, M. Haghshenas, N. Abdullah, R. Rosli, D. Radiah, and A. Yari Khosroushahi. 2015. Bioactivity characterization of Lactobacillus strains isolated from dairy products. MicrobiologyOpen 4:803-813.

Ispirli, H., F. Demirbas, and E. Dertli. 2016. Characterization of functional properties of Enterococcus spp. isolated from Turkish white cheese. Lebensm. Wiss. Technol. 75:358-365.

Krasaekoopt, W., B. Bhandari, and H. Deeth. 2004. Comparison of texture of yogurt made from conventionally treated milk and UHT milk fortified with low-heat skim milk powder. J. Food Sci. 69:276-280.

Lee, W. J., and J. A. Lucy. 2006. Impact of gelation condition sand structural breakdown on the physical and sensory properties of stirred yogurts. J. Dairy Sci. 89:2374-2385.

Li, Y., W. Zhang, D. Zheng, Z. Zhou, W. Yu, L. Zhang, L. Feng, X. Liang, W. Guan, J. Zhou, J. Chen, and Z. Lin. 2014. Genomic evolution of Saccharomyces cerevisiae under Chinese rice wine fermentation. Genome Biol. Evol. 6:2516-2526.

Liu, W. J., Z. H. Sun, Y. B. Zhang, and C. L. Zhang. 2012. A survey of the bacterial composition of kurut from Tibet using a cultureindependent approach. J. Dairy Sci. 95:1064-1072.

Lucey, J. A., and H. Singh. 1999. Effects of heat treatment and whey protein addition on the rheological properties and structure of acid skim milk gels. Int. Dairy J. 9:275-279. 
Lv, X. C., X. Weng, W. Zhang, P. F. Rao, and L. Ni. 2012. Microbial diversity of traditional fermentation starters for Hong Qu glutinous rice wine as determined by PCR-mediated DGGE. Food Control 34:183-190.

Matumoto-Pintro, P. T., L. Rabiey, G. Robitaille, and M. Britten. 2011. Use of modified whey protein in yoghurt formulations. Int. Dairy J. 21:21-26.

Mercan, E., and N. Akin. 2016. Effect of different levels of pine honey addition on physicochemical, microbiological and sensory properties of set-type yoghurt. Int. J. Dairy Technol. 70:245-252.

Mercan, E., D. Sert, E. Karakavuk, and N. Akin. 2018. Effect of different levels of grapeseed (Vitis vinifera) oil addition on physicochemical, microbiological and sensory properties of set-type yoghurt. Int. J. Dairy Technol. 71:34-43.

Muyzer, G., E. C. Dewaal, and A. G. Uitterlinden. 1993. Profiling of complex microbial populations by denaturing gradient gel electrophoresis analysis of polymerase chain reaction-amplified genes encoding for 16S rRNA. Appl. Environ. Microbiol. 59:695-700.

Muyzer, G., and K. Smalla. 1998. Application of denaturing gradient gel electrophoresis (DGGE) and temperature gradient gel electrophoresis (TGGE) in microbial ecology. Antonie Van Leeuwenhoek 73:127-141.

Onyeneho, S. N., J. A. Patridge, J. R. Brunner, and J. Guan. 1987. Manufacture and characterization of Gua-Nai: A new dairy food produced with an oriental-type culture. J. Dairy Sci. 70:2499-2503.

Park, Y. W., M. Juárez, M. Ramos, and G. F. W. Haenlein. 2007. Physico-chemical characteristics of goat and sheep milk. Small Rumin. Res. 68:88-113.

Rahman, N., C. Xiaohong, F. Meiqin, and D. Mingsheng. 2009. Characterization of the dominant microflora in naturally fermented camel milk shubat. World J. Microb. Biot. 25:1941-1946.

Sah, B., T. Vasiljevic, S. Mckechnie, and O. Donkor. 2016. Physicochemical, textural and rheological properties of probiotic yogurt fortified with fibre-rich pineapple peel powder during refrigerated storage. LWT Food Sci. Technol. 65:978-986.

Sandoval-Castilla, O., C. Lobato-Calleros, E. Aguirre-Mandujano, and E. J. Vernon-Carter. 2004. Microstructure and texture of yogurt as influenced by fat replacers. Int. Dairy J. 14:151-159.
Sert, D., E. Mercan, and E. Dertli. 2017. Characterization of lactic acid bacteria from yogurt-like product fermented with pine cone and determination of their role on physicochemical, textural and microbiological properties of product. Lebensm. Wiss. Technol. 78:70-76.

Su, L. C., C. W. Lin, and M. J. Chen. 2005. Studies of the microbial and physical properties of Oriental style dairy product Kou Woan Lao with probiotics. Asian-Australas. J. Anim. Sci. 18:409-413.

Terpou, A., A. Papadaki, L. Bosnea, L. Bosnea, M. Kanellaki, and N. Kopsahelis. 2019. Novel frozen yogurt production fortified with sea buckthorn berries and probiotics. Lebensm. Wiss. Technol. 105:242-249.

Thanh, V. N., N. T. Thuy, N. T. Chi, D. D. Hien, B. T. Ha, D. T Luong, P. D. Nqoc, and P. V. Ty. 2016. New insight into microbial diversity and functions in traditional Vietnamese alcoholic fermentation. Int. J. Food Microbiol. 232:15-21.

Wang, C. L., D. J. Shi, and G. L. Gong. 2008. Microorganisms in Daqu: A starter culture of Chinese Maotai-flavor liquor. World J. Microb. Biot. 24:2183-2190.

Wang, Q. M., W. Q. Liu, G. Liti, S. A. Wang, and F. Y. Bai. 2012 Surprisingly diverged populations of Saccharomyces cerevisiae in natural environments remote from human activity. Mol. Ecol. 21:5404-5417.

\section{ORCIDS}

Shaoying Gong @ https://orcid.org/0000-0002-2062-6188

Peng Fei ৫ https://orcid.org/0000-0001-7895-4603

Aslam Ali $\odot$ https://orcid.org/0000-0002-6382-2787

Xiaolin Cai ৫ https://orcid.org/0000-0003-0371-5477

Ling Guo () https://orcid.org/0000-0002-5743-098X 